\title{
VARIAÇÃO LINGUÍSTICA DAS VOGAIS MÉDIAS PRETÔNICAS EM CONTEXTO MEDIAL NO NOROESTE PAULISTA
}

\section{LINGUISTIC VARIATION OF WORD-MEDIAL PRETONIC MID-VOWELS IN THE NORTHWEST OF SÃO PAULO STATE}

\author{
Márcia Cristina do Carmo*
}

Resumo: este artigo apresenta os principais resultados da pesquisa de Doutorado As vogais médias pretônicas na variedade do interior paulista (CARMO, 2013), que analisa o alçamento variável das vogais médias pretônicas mediais no noroeste paulista, como em $p[i] q u e n o \sim p[e] q u e n o$ e $c[u]$ sturando $\sim c[0]$ sturando. O córpus é constituído por amostras de fala espontânea de 38 inquéritos do banco de dados IBORUNA (Projeto ALIP - IBILCE/UNESP - FAPESP 03/08058-6). Segue-se a Teoria da Variação e Mudança Linguística (LABOV, 2008 [1972]), com a utilização do pacote estatístico Goldvarb X. Como resultado geral, destaca-se a atuação do processo de harmonização vocálica (CÂMARA JR., 2007 [1970]; BISOL, 1981), indicada pela seleção da altura da vogal presente na sílaba subsequente à sílaba da pretônica-alvo como a variável mais relevante para a aplicação do alçamento, independentemente da classe gramatical do vocábulo. PALAVRAS-CHAVE: variação fonológica; vogais médias pretônicas; alçamento vocálico.

ABstRACT: This paper presents the primary findings of the $\mathrm{PhD}$ thesis As vogais médias pretônicas na variedade do interior paulista ('Pretonic Mid-vowels in the Variety of Paulista Inland') (CARMO, 2013), which analyses the variable raising of word-medial pretonic mid-vowels, e.g. p[i]queno p [e]queno ('small'/'little') and c[u]sturando $\sim c[0]$ sturando ('sewing'), in the Northwest of São Paulo State. The corpus of this study consists of spontaneous speech samples of 38 interviews taken from the IBORUNA database (ALIP Project - IBILCE/UNESP - FAPESP 03/08058-6). This work follows the Theory of Linguistic Variation and Change (LABOV, 2008 [1972]) and utilises the statistical package Goldvarb X. As a general result, the relevance of vowel harmony (CÂMARA JR., 2007 [1970]; BISOL, 1981) to the application of vowel raising is highlighted, as

\footnotetext{
"Docente adjunta vinculada ao Departamento de Estudos da Linguagem da Universidade Estadual de Ponta Grossa (DEEL/UEPG). Doutora em Estudos Linguísticos pela Universidade Estadual Paulista (UNESP/IBILCE). Realizou Pós-Doutorado na University College London (UCL/Reino Unido). E-mail: mccarmo@uepg.br.
} 
indicated by the selection of the height of the vowel in the subsequent syllable as the most relevant variable, regardless of the grammatical class of the word.

KEYwORDS: phonological variation; pretonic mid-vowels; vowel raising.

\section{INTRODUÇÃO}

Este trabalho é fruto da tese de Doutorado As vogais médias pretônicas na variedade do interior paulista (CARMO, 2013), ${ }^{1}$ sumarizando e trazendo para o gênero artigo seus principais resultados, que discutem o comportamento fonético-fonológico variável das vogais médias pretônicas /e, o/ em contexto de meio de vocábulo na variedade do interior paulista, onde está situado o município de São José do Rio Preto.

Essas vogais estão suscetíveis à aplicação do fenômeno denominado alçamento, em que as vogais médias-altas /e/ e /o/ são pronunciadas, respectivamente, como as altas [i] e $[u]$, como em $m[i]$ nino $\sim m[e]$ nino e $c[u]$ nsertar $\sim c[0]$ nsertar. Esse fenômeno pode resultar de dois processos, a saber: harmonização vocálica (CÂMARA JR., 2007 [1970]; BISOL, 1981), ${ }^{2}$ em que uma vogal alta na sílaba imediatamente seguinte à da pretônica-alvo engatilha o alçamento, como em inv[i]sti e s[u]frido; e (ii) redução vocálica (ABAURRE-GNERRE, 1981), em que se pode verificar a influência do ponto de articulação da(s) consoante(s) adjacente(s) à pretônica-alvo para a aplicação do fenômeno, como em $p[i k] e n o$ e al[mu]çar.

O comportamento variável das vogais médias pretônicas tem sido investigado no que tange a diferentes variedades do Português Brasileiro (doravante, PB) pelo fato de marcar variação dialetal. No Estado de São Paulo, todavia, os estudos acerca dessa temática são relativamente recentes. A presente pesquisa avança em comparação às dissertações de Silveira (2008) e Carmo (2009), por comparar conjunta e sistematicamente o alçamento em diferentes classes gramaticais, a saber: nomes e verbos. Ademais, avança em relação ao estudo de Carmo e Tenani (2013), por apresentar uma análise detalhada das rodadas distintas efetuadas para essas classes gramaticais.

Cabe ressaltar, também, que esta pesquisa contribui no âmbito de um Projeto maior ao qual está vinculada: Descrição Sócio-Histórica das Vogais do Português (do Brasil) (PROBRAVO), ${ }^{3}$ que conduz investigações sócio-históricas e linguísticas sobre as realizações fonético-fonológicas das vogais em diferentes variedades do $\mathrm{PB}$.

O presente artigo está estruturado do seguinte modo: na seção 2, apresentam-se os processos relacionados ao alçamento vocálico e a Teoria da Variação e Mudança Linguística (LABOV, 2008 [1972]), que embasa teoricamente a presente pesquisa. Na seção 3, descrevem-se o córpus, as variáveis investigadas e os passos metodológicos efetuados durante a realização da investigação. Na seção 4, é feita a análise dos dados. Finalmente, na seção 5, são apresentadas as considerações finais, seguidas pelas referências bibliográficas. 


\section{FUNDAMENTAÇÃO TEÓRICA}

Em relação às vogais orais no PB, Câmara Jr. (2007 [1970], p. 41) afirma haver sete vogais em posição tônica, a saber: /i, e, E, a, O, o, u/. ${ }^{4}$ Segundo o autor, na posição pretônica, há uma redução para cinco fonemas vocálicos, por meio do processo de neutralização: /i, e, a, o, u/.

As vogais médias pretônicas /e/ e /o/ no interior paulista estão sujeitas à aplicação variável do fenômeno fonológico denominado alçamento vocálico, sendo pronunciadas como as altas [i] e [u], respectivamente, como em p[i]dido e c[u]ntinua. ${ }^{5}$

Dois processos podem acarretar a aplicação do alçamento: (i) harmonização vocálica (CÂMARA JR., 2007 [1970]; BISOL, 1981), em que uma vogal alta na sílaba subsequente à da pretônica-alvo engatilha o fenômeno, como em pr[i]cisava e op [u]rtunidade; e (ii) redução vocálica (ABAURRE-GNERRE, 1981), em que, geralmente, é observada a influência do(s) ponto(s) de articulação da(s) consoante(s) adjacente(s), como em p [ik]eno e al[mu]çar.

No que concerne a estudos prévios realizados sobre vogais médias pretônicas em contexto medial na variedade do noroeste paulista, Silveira (2008) observou que o processo de redução vocálica é o mais relevante para o alçamento das vogais médias pretônicas dos nomes. Carmo (2009), por sua vez, identificou a harmonização vocálica como o processo mais atuante para o alçamento das vogais médias pretônicas em verbos. Como justificativa, a autora aponta a existência de sufixos de segunda e de terceira conjugações /-i/ e /-ia/ e a ocorrência de harmonia vocálica na raiz de certas formas verbais de terceira conjugação, como em sentir - sinto e dormir - durmo. Realizar uma comparação mais sistemática - considerando, por exemplo, as mesmas variáveis para nomes e verbos - foi uma das motivações para a realização deste estudo. Em outras palavras, objetiva-se verificar o papel da classe gramatical no comportamento variável das vogais médias pretônicas na variedade estudada.

As vogais médias pretônicas no noroeste paulista são analisadas no presente artigo à luz do arcabouço teórico da Teoria da Variação e Mudança Linguística (LABOV, 2008 [1972]), também denominada Sociolinguística quantitativa. ${ }^{6}$

De acordo com Calvet (2002 [1993]), os anos 1970 corresponderam a uma virada nos estudos linguísticos, com a publicação de revistas e coletâneas de artigos sobre Sociolinguística, "que adquire mais e mais importância e vem deslocar posições consideradas definitivas" (CALVET, 2002 [1993], p. 33). A Teoria da Variação e Mudança Linguística focaliza seus estudos

\footnotetext{
${ }^{4}$ No presente artigo, por questões de natureza tipográfica, as vogais médias-baixas anterior e posterior são apresentadas, respectivamente, como /E/ e/O/.

${ }^{5}$ É digna de nota a ausência, nessa variedade, do abaixamento vocálico, por meio do qual as vogais médias-altas são pronunciadas, respectivamente, como as médias-baixas [E] e [O], como em $p[E] r[E] r e c a$ e $c[O] l e g a$. Esse fenômeno é característico, sobretudo, do Norte e do Nordeste brasileiros, mas também pode ser identificado em determinadas variedades do Centro-Oeste e do Sudeste do país.

${ }^{6}$ Labov (2008 [1972]) ressalta a redundância do termo "sociolinguística", posto que a língua é sempre atrelada ao comportamento social.
} 
na língua em uso dentro da comunidade de fala, rompendo com a tradição estruturalista proposta por Saussure no início do século XX. Labov (2008 [1972]) critica o paradoxo saussuriano de o aspecto social da língua (langue ou língua, na dicotomia saussuriana) ser estudado pela observação do indivíduo, enquanto o aspecto individual (parole ou fala, descartada pela proposta estruturalista), pela verificação da língua em seu contexto social.

De modo análogo, critica o gerativismo proposto por Chomsky, especialmente no que tange (i) ao seu objeto, relativo a uma comunidade de fala abstrata e homogênea; e (ii) aos seus dados, provenientes de julgamentos intuitivos de falantes nativos acerca de sua língua.

Nesse âmbito, a Teoria da Variação e Mudança Linguística difere-se dessas correntes teóricas por eliminar a associação entre estrutura e homogeneidade, propondo, como objeto de estudos, a heterogeneidade inerente ao sistema linguístico, sendo a língua o instrumento de comunicação utilizado pela comunidade de fala.

A existência de variação e de estruturas heterogêneas nas comunidades de fala investigadas está certamente bem fundamentada nos fatos. É a existência de qualquer outro tipo de comunidade de fala que deve ser posta em dúvida. [...] A heterogeneidade não é apenas comum, ela é o resultado natural de fatores linguísticos fundamentais (LABOV, 2008 [1972], p. 238, grifo do autor).

Conforme afirmam Weinreich, Labov e Herzog (2006 [1968]), uma variável linguística é definida por funções de variáveis independentes linguísticas e extralinguísticas, mas não necessariamente independentes umas das outras. De acordo com os autores, nem toda heterogeneidade linguística resulta em mudança. Porém, toda mudança implica variação prévia.

Partindo da variação, a mudança linguística inicia-se quando a generalização de uma alternância em certo subgrupo específico de falantes toma determinada direção, assumindo o caráter de uma diferenciação ordenada. Para sua implementação efetiva, há uma perda de significações sociais que a variante originalmente possuía (WEINREICH; LABOV; HERZOG, 2006 [1968]).

Ainda sobre a literatura acerca de mudança linguística, esta é descrita, sobretudo, segundo duas abordagens/hipóteses: a difusão lexical e a neogramática. Na primeira, cada vocábulo apresenta sua própria história, e as mudanças, implementadas a partir do léxico, são foneticamente abruptas e lexicalmente graduais. Por sua vez, na segunda, todas as palavras são atingidas indistintamente pela mudança linguística (mudanças lexicalmente abruptas e foneticamente graduais) e as eventuais exceções à regra são explicadas por analogia.

Segundo Bisol (2009), a harmonização vocálica - assim como o alçamento da pretônica /e/ inicial antecedendo $\mathrm{N}$ ou S - pode ser explicada de acordo com a perspectiva neogramática. A autora afirma ser a harmonização, 
inegavelmente, uma regra neogramática, dependente do sistema, favorecida por certos contextos, o que não a impede de ser aplicada em contextos menos favorecedores, em virtude de seu caráter variável, sempre, porém, sob a égide de seu condicionador fonético, a vogal alta seguinte (BISOL, 2009, p. 87).

Por sua vez, a redução vocálica, por não ter um condicionador fonético específico e por contar com propriedades do próprio fonema (a vogal média é naturalmente a mais suscetível à mudança sonora), é passível de explicação, conforme a autora, segundo a hipótese difusionista.

Passa-se, agora, à descrição do córpus e dos passos metodológicos empregados nesta pesquisa.

\section{MATERIAL E MÉTODOS}

Como corpus desta investigação, foram consideradas 38 entrevistas ${ }^{7}$ retiradas do banco de dados IBORUNA (GONÇALVES, 2007; 2018), resultado do Projeto ALIP (FAPESP 03/080586), sediado no IBILCE/UNESP. Esse banco de dados, disponível em <iboruna.ibilce.unesp. br>, conta com amostras de fala espontânea de informantes de São José do Rio Preto e de seis cidades circunvizinhas: Bady Bassit, Cedral, Guapiaçu, Ipiguá, Mirassol e Onda Verde.

De cada um dos informantes, foram colhidos cinco tipos de relatos, sendo eles: (i) narrativa de experiência pessoal; (ii) narrativa de experiência recontada; (iii) descrição; (iv) procedimento; e (v) opinião. Para a presente pesquisa, foram consideradas apenas as narrativas de experiência pessoal, por se tratar de um gênero em que o informante desvia sua atenção para o quê fala, ao invés do modo como fala. Labov (2008 [1972]) destaca a importância de serem obtidos dados que se aproximem o máximo possível do vernáculo do informante. Ao ser entrevistado, o falante tende a usar um estilo linguístico mais policiado, utilizando o estilo mais casual em outras situações, quando discute com os amigos, por exemplo. Segundo Labov (2003; 2008 [1972]), uma das técnicas para obter fala casual em uma situação de entrevista é fazer com que o informante seja envolvido emocionalmente por meio de perguntas que recriem o que vivenciou, pois, ao se envolver com o assunto sobre o qual está falando, deixa de monitorar sua fala.

Este estudo apresenta, como variável dependente, a alternância das vogais médias pretônicas em contexto medial no falar do noroeste paulista. Quanto às variáveis independentes, são consideradas sete de natureza linguística e três sociais, devidamente apresentadas e justificadas no quadro 1, exposto a seguir.

\footnotetext{
${ }^{7}$ No presente trabalho, são analisadas as falas de informantes de 2 sexos/gêneros, 5 faixas etárias e 4 graus de escolaridade, o que totalizaria 40 entrevistas ( $2 \times 5 \times 4)$. Deve-se ressaltar, porém, que não há informantes - tanto do sexo masculino quanto do sexo feminino - pertencentes à faixa etária de 7 a 15 anos que estejam cursando ou que tenham completado o Ensino Superior. Desse modo, são 38 os inquéritos analisados nesta pesquisa.
} 
Quadro 1-Variáveis independentes analisadas ${ }^{8}$

\begin{tabular}{|c|c|}
\hline Variável & Justificativa/hipótese \\
\hline $\begin{array}{l}\text { Altura da vogal } \\
\text { presente na sílaba } \\
\text { subsequente à sílaba } \\
\text { da pretônica-alvo }\end{array}$ & $\begin{array}{l}\text { Tem-se a hipótese de que as vogais altas, como em } m[i] n t i r a \text { e pr[u]curava, por } \\
\text { meio do processo de harmonização vocálica, favoreçam o alçamento, ao pas- } \\
\text { so que vogais médias-altas, como em p[e]guei e desc[o]ntrolado, médias-baixas, } \\
\text { como em env[e]lhece e polv[o]rosa, e baixa, como em s[e]ntada e b[o]tava, ten- } \\
\text { dam a inibi-lo. }\end{array}$ \\
\hline $\begin{array}{l}\text { Tonicidade da vogal } \\
\text { presente na sílaba } \\
\text { subsequente à sílaba } \\
\text { da pretônica-alvo }\end{array}$ & $\begin{array}{l}\text { Por meio do cruzamento com a altura da vogal presente na sílaba subsequente } \\
\text { à sílaba da pretônica-alvo, objetiva-se analisar, com base em Câmara Jr. (2007 } \\
\text { [1970]) e Bisol (1981), em que medida a tonicidade da vogal alta, gatilho à har- } \\
\text { monização, é relevante para a aplicação do processo, isto é, se a presença de } \\
\text { vogal alta átona na sílaba seguinte, como em m[o]bilidâde e pr[o]curarr, exerce } \\
\text { a mesma influência que a presença de uma vogal alta tônica, como em p[i]dído } \\
\text { e d[u]rmía. }\end{array}$ \\
\hline $\begin{array}{l}\text { Distância entre a } \\
\text { sílaba da vogal alta } \\
\text { em relação à sílaba } \\
\text { da pretônica-alvo }\end{array}$ & $\begin{array}{l}\text { Com essa variável, busca-se corroborar a afirmação de Bisol (1981) de que esse } \\
\text { processo não dá saltos, por envolver articulações sucessivas. Desse modo, os } \\
\text { fatores são: (i) presença de vogal alta na sílaba seguinte, como em a.cr[e].di.ta. } \\
\text { va e c[o]ns.tru.ir; (ii) distância de uma sílaba, como em } p[e] r . c e . b i \text { e } c[0] . n h e . c i \text {; e } \\
\text { (iii) distância de duas sílabas, como em r[e]s.pon.sa.bi.li.da.de. Vocábulos como } \\
c[u] n h[e] c e n d o, \text { sem vogal alta, foram computados como não se aplica. }\end{array}$ \\
\hline $\begin{array}{l}\text { Grau de atonicidade } \\
\text { da pretônica-alvo }\end{array}$ & $\begin{array}{l}\text { A hipótese é a de que as vogais que permanecem átonas, como } p[e] r i g o-p[e] r i- \\
\text { culosidade, têm maiores índices de alçamento do que aquelas que apresentam } \\
\text { atonicidade variável, como ad[o]rar-ad[O]ro. Isso se justifica justamente pelo } \\
\text { fato de terem um caráter permanentemente átono e, assim, estarem sujeitas } \\
\text { a alterações (BISOL, 1981). No entanto, espera-se que a atonicidade variável } \\
\text { com uma vogal alta como tônica, como d[u]rmia-durmo, seja o contexto mais } \\
\text { favorecedor do alçamento, devido à influência da harmonia vocálica na raiz } \\
\text { verbal. }\end{array}$ \\
\hline $\begin{array}{l}\text { Ponto de articulação } \\
\text { da consoante } \\
\text { precedente à } \\
\text { pretônica-alvo }\end{array}$ & $\begin{array}{l}\text { A hipótese é a de que a pretônica /e/, coronal, tenha seu alçamento propiciado } \\
\text { por consoante(s) coronal(is), como em prot [e]ção, ao passo que /o/, dorsal e la- } \\
\text { bial, tenha seu alçamento favorecido por consoante(s) que apresentam esses } \\
\text { pontos de articulação, como em } \boldsymbol{c}[0] \text { rrendo e } \boldsymbol{p}[0] \text { legadas. }\end{array}$ \\
\hline $\begin{array}{l}\text { Ponto de articulação } \\
\text { da consoante } \\
\text { subsequente à } \\
\text { pretônica-alvo }\end{array}$ & 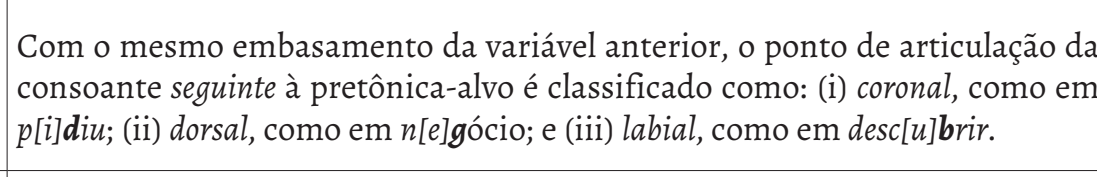 \\
\hline $\begin{array}{l}\text { Estrutura da sílaba } \\
\text { em que a pretônica- } \\
\quad \text { alvo ocorre }\end{array}$ & $\begin{array}{l}\text { A partir da noção de sílaba proposta para o Português (SELKIRK, 1982; } \\
\text { COLLISCHONN, 1999), objetiva-se investigar, por exemplo, se a estrutura } \\
\text { silábica com coda apresenta comportamento diferente de sem coda para o } \\
\text { alçamento. }\end{array}$ \\
\hline
\end{tabular}

$\overline{{ }^{8} \mathrm{O} \text { quadro } 1}$, bem como todas as tabelas apresentadas neste artigo, resultam de elaboração própria. 
conclusão

\begin{tabular}{|c|l|}
\hline Variável & \multicolumn{1}{c|}{ Justificativa/hipótese } \\
\hline Sexo/gênero & $\begin{array}{l}\text { Busca-se averiguar eventual indício de estigma do alçamento na variedade } \\
\text { do noroeste paulista, posto que pesquisas sociolinguísticas têm constatado } \\
\text { que as mulheres usam variantes estigmatizadas e não-padrão com menos } \\
\text { frequência do que os homens do mesmo grupo social a que pertencem } \\
\text { (CHAMBERS, 2009 [1995]; LABOV, 2003; 2008 [1972]). }\end{array}$ \\
\hline Faixa etária & $\begin{array}{l}\text { Objetiva-se investigar o status do fenômeno variável como estável ou mudança } \\
\text { em progresso, já que essa variável é capaz de indicar mudança em tempo } \\
\text { aparente. }\end{array}$ \\
\hline Escolaridade & $\begin{array}{l}\text { Busca-se detectar eventual influência da educação formal no alçamento } \\
\text { vocálico no interior paulista, podendo indicar, também, estigma social em } \\
\text { relação ao fenômeno. }\end{array}$ \\
\hline
\end{tabular}

Após a seleção do córpus e extração de cada ocorrência de vogal média pretônica, foram identificados os contextos em que estava inserida e seu comportamento em relação ao alçamento vocálico. No entanto, deve-se destacar que ocorrências de vogais médias pretônicas presentes em determinados contextos foram excluídas, sendo eles:

(i)Início de vocábulo: como em [i]scritório e [o]perou, com base na afirmação de Bisol (1981) de que os princípios que regem o alçamento da vogal inicial não se identificam com aqueles referentes ao alçamento da pretônica interna; ${ }^{2}$

(ii) Ditongo: como em tr[e]inamento e s[o]ubesse, pelo fato de as vogais médias pretônicas serem seguidas por semivogais ou glides, os quais não têm as mesmas propriedades de vogais plenas e, por isso, não devem ser analisadas como gatilho da harmonização vocálica. Ademais, nesse contexto, pode ser encontrado outro processo fonológico: a monotongação, fazendo com que esse contexto mereça um estudo à parte;

(iii) Hiato: como em apr[ie]nsivas e j[ue]lho, contexto em que, segundo Bisol (1981), o alçamento sobrepõe o da vogal pretônica entre consoantes. Tal fato também foi verificado no tangente às vogais médias pretônicas na variedade do interior paulista, especialmente quando essa vogal é seguida por /a/ tônico, como em massag[i]ando e raz[u]áveis, contexto destacado por Câmara Jr. (2007 [1970]), por, nele, a aplicação do alçamento ser favorecida;

(iv) Prefixo: como em $r$ [e]fiz e $m$ [o]nocultura, pois certos prefixos não se incorporam totalmente ao vocábulo com que combinam, possuindo traços

\footnotetext{
${ }^{9}$ Informações sobre as vogais médias pretônicas especificamente em contexto de início de vocábulo no noroeste paulista podem ser encontradas no artigo de Carmo (2019).
} 
de composição, que consiste em um ambiente pouco propício para o alçamento decorrente de harmonização vocálica (BISOL, 1981). Além disso, Bisol (1981) aponta o fato de a vogal presente em prefixo poder, em muitos casos, ser elidida.

Após a exclusão das ocorrências presentes nesses contextos, foi feita a análise do conjunto de dados restante, procedendo à análise de oitiva ${ }^{10} \mathrm{e}$ a uma quantificação dos resultados obtidos. A análise estatística dos dados foi feita por programas do pacote estatístico Goldvarb $\mathrm{X}$ e os resultados encontrados são descritos na seção a seguir.

\section{DESCRIÇÃO E ANÁLISE DOS DADOS}

Uma primeira rodada investigou todas as ocorrências de vogais médias pretônicas conjuntamente, ${ }^{11}$ a fim de se observar o panorama geral do alçamento dessas vogais em contexto medial na variedade do noroeste paulista. Como apontam Carmo e Tenani (2013), a classe gramatical foi descartada pelo programa estatístico. Desse descarte, pode-se inferir que o fato de a vogal média pretônica pertencer a um nome ou a um verbo não apresenta diferença significativa em relação ao alçamento dessa vogal. Apesar desse resultado, optou-se pela realização de rodadas distintas para nomes e verbos, a fim de se investigar sistematicamente se, de fato, não há comportamento diferenciado das vogais médias pretônicas em cada classe gramatical. ${ }^{12}$

Dessa forma, as quatro rodadas seguintes analisaram, separadamente, as ocorrências de vogais pretônicas /e/ e /o/ em nomes e verbos. O resultado referente à aplicação geral do alçamento vocálico em cada rodada pode ser observado a partir da tabela a seguir:

Tabela 1 - Aplicação do alçamento em relação à vogal pretônica-alvo e à classe gramatical

\begin{tabular}{cc|c|c|c}
\hline & \multicolumn{2}{c|}{ Pretônica /e/ } & \multicolumn{2}{c}{ Pretônica /o/ } \\
\cline { 2 - 5 } & Nomes & Verbos & Nomes & Verbos \\
\cline { 2 - 5 } & $14,7 \%(193 / 1315)$ & $17,3 \%(281 / 1621)$ & $16,1 \%(125 / 774)$ & $16,9 \%(212 / 1257)$ \\
\hline \multirow{2}{*}{ Total } & \multicolumn{2}{c}{$\mathbf{1 6 , 1} \%(474 / 2936)$} & \multicolumn{2}{c}{$\mathbf{1 6 , 6 \% ( 3 3 7 / 2 0 3 1 )}$} \\
\hline
\end{tabular}

De modo geral, verificam-se índices percentuais de alçamento relativamente semelhantes para cada rodada, especialmente no que diz respeito à pretônica /o/: 16,1\% para em nomes

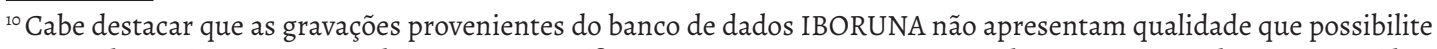
uma análise acústica por meio de recursos específicos, como o programa PRAAT. Nelas, são encontrados muitos ruídos, decorrentes, principalmente, do fato de as entrevistas não terem sido realizadas em cabines com isolamento acústico, o que justifica a não-realização de análise acústica dos dados nesta pesquisa.

${ }^{11}$ Resultados referentes a essa primeira rodada podem ser encontrados detalhadamente no artigo publicado por Carmo e Tenani (2013).

${ }^{12}$ Consequentemente, este trabalho avança em relação aos resultados de Carmo e Tenani (2013).
} 
e $16,9 \%$ em verbos. A diferença entre as porcentagens de alçamento da vogal /e/ em nomes e verbos é maior, havendo taxa de alçamento mais alta em verbos $(17,3 \%)$ do que em nomes (14,7\%). A existência de porcentagens de alçamento maiores em verbos do que em nomes pode ser justificada pelas características morfofonológicas da classe gramatical dos verbos, com destaque aos de terceira conjugação, que apresentam vogal temática /i/, sufixos verbais com vogal alta e o processo de harmonia vocálica na raiz de algumas de suas formas.

Deve-se destacar que, nas quatro rodadas, a altura da vogal presente na sílaba subsequente à sílaba da pretônica-alvo foi considerada, tanto para /e/ quanto para /o/, a variável mais relevante para a aplicação do alçamento. Tal resultado evidencia a importância da harmonização vocálica na realização do alçamento das vogais médias pretônicas na variedade do interior paulista, o que será corroborado por resultados dos fatores referentes a vogais altas, exibidos mais adiante (cf. tabelas 2 e 3 ).

Outro fato que deve ser destacado é a influência relativamente baixa que as variáveis extralinguísticas exercem em relação ao alçamento vocálico nessa variedade. Para as vogais médias pretônicas /e/ e /o/ em nomes, as variáveis sociais foram descartadas. Para /e/ em verbos, apenas a escolaridade e a faixa etária foram selecionadas, ocupando as últimas posições em grau de importância. Para/o/ em verbos, apenas o sexo/gênero foi apontado como relevante, estando na penúltima posição como variável mais significativa no alçamento dessa vogal. Dessa maneira, pode-se afirmar que o alçamento das vogais médias pretônicas na variedade do interior paulista é um fenômeno relacionado, sobretudo, a informações linguísticas. Outro resultado importante que diz respeito à variável social é o fato de a faixa etária não ter sido selecionada para a vogal pretônica /e/ em nomes e para /o/ em nomes e verbos, o que mostra que, para essas vogais, tal fenômeno se encontra em variação estável.

Por conseguinte, dado o recorte necessário para a elaboração do presente artigo, este elenca os resultados principais acerca do comportamento variável das vogais médias pretônicas no noroeste paulista, que dizem respeito às variáveis linguísticas relacionadas à harmonização vocálica, destacada como processo mais atuante (cf. CARMO, 2013). ${ }^{13}$

Como mencionado, a altura da vogal presente na sílaba subsequente à sílaba da pretônica-alvo foi a variável apontada como a mais relevante à aplicação do alçamento vocálico tanto de /e/ quanto de /o/, em nomes e em verbos, o que fornece fortes indícios sobre a influência da harmonização vocálica no alçamento das vogais médias pretônicas na variedade do interior paulista. Essa informação é corroborada quando observados os resultados dos fatores relacionados à presença de vogal alta na sílaba seguinte à da pretônica-alvo. Para a vogal/e/, esses resultados podem ser verificados na tabela 2 , a seguir:

${ }^{13}$ Para os demais resultados, recomenda-se a leitura da tese de Doutorado de Carmo (2013). 
Tabela 2 - Alçamento de /e/ em nomes e verbos em relação à altura da vogal presente na sílaba subsequente à sílaba da pretônica-alvo

\begin{tabular}{|c|c|c|c|c|}
\hline & \multicolumn{2}{|c|}{ Pretônica /e/ - Nomes } & \multicolumn{2}{|c|}{ Pretônica /e/ - Verbos } \\
\hline & Frequência & PR & Frequência & PR \\
\hline Alta anterior & $34,2 \%(117 / 342)$ & 0.876 & $61,1 \%(232 / 380)$ & 0.967 \\
\hline Alta posterior & $12 \%(6 / 50)$ & 0.319 & $32,5 \%(13 / 40)$ & 0.928 \\
\hline Média-alta & $11,2 \%(54 / 480)$ & 0.514 & $4,3 \%(35 / 805)$ & 0.385 \\
\hline $\begin{array}{c}\text { Média-baixa ou } \\
\text { baixa }\end{array}$ & $3,6 \%(16 / 443)$ & 0.185 & $0,3 \%(1 / 396)$ & 0.072 \\
\hline Total & \multicolumn{2}{|c|}{$14,7 \%(193 / 1315)$} & \multicolumn{2}{|c|}{$17,3 \%(281 / 1621)$} \\
\hline & \multicolumn{2}{|c|}{ Input: 0.104} & \multicolumn{2}{|l|}{ Input: 0.052} \\
\hline & \multicolumn{2}{|l|}{ Signif.: 0.001} & \multicolumn{2}{|l|}{ Signif.: 0.007} \\
\hline
\end{tabular}

Em relação à pretônica /e/, a vogal alta anterior favorece o alçamento em nomes (peso relativo - doravante, PR-0.876), como em v[i]sícula, e em verbos (PR 0.967), como em rep[i]tiu. Em relação ao fator vogal alta posterior, observam-se resultados aparentemente diferentes para nomes e verbos. Nos nomes, como em j[e]jum, a vogal alta é apontada como desfavorecedora do alçamento (PR 0.319), ao passo que, nos verbos, como em s[i]gurar, essa vogal é altamente favorecedora (PR 0.928).

A princípio, esperava-se que a vogal alta posterior favorecesse o alçamento também em nomes, por atuar como gatilho no processo de harmonização vocálica, independentemente da classe gramatical do vocábulo. A partir desse resultado inesperado, foram verificados os dados alçados seguidos de vogal alta posterior em cada classe gramatical. Observa-se que 6 ocorrências de alçamento de /e/ em nomes (nos vocábulos s[i]gunda-feira, s[i]gura es[i]gurança) e 10 (em s[i]gurando, s[i]gurar, s[i]gurasse, s[i]gurei e s[i]gurou) dos 13 casos $^{14}$ de alçamento de /e/ em verbos correspondem a um mesmo contexto fonológico: a vogal pretônica é antecedida pela consoante coronal /s/ e seguida pela dorsal /g/. Como mostrado mais adiante, a consoante dorsal em posição subsequente favorece o alçamento de /e/ em nomes e em verbos e, portanto, a redução vocálica pode explicar o alçamento nesses casos.

Sendo assim, de modo geral, as ocorrências de alçamento de /e/ com vogal /u/ na sílaba seguinte em nomes e verbos parecem corresponder a contextos semelhantes e, portanto, não se pode afirmar que a vogal alta posterior desfavoreça o alçamento em uma classe gramatical e o favoreça em outra, como indicado na tabela 2.

Podem ser observados, também, maiores PRs concernentes à vogal alta anterior, quando comparada à vogal alta posterior. Essa diferença de comportamento por parte de /i/ e de /u/ em relação ao alçamento de /e/ pode ser justificada pela posição mais alta da língua na

${ }^{14}$ As exceções são os vocábulos $d[i]$ rrubar, d[i]rrubou e p[i]ndurava. 
cavidade bucal durante a realização da vogal alta anterior (BISOL, 1981). Pelo fato de /u/ ser menos alta do que /i/, "é natural que não exerça sua força atrativa sobre /e/, pois convertê-la em /i/ seria provocar uma articulação mais alta que a própria” (BISOL, 1981, p. 114). Justificase, dessa forma, o favorecimento do alçamento de /e/ principalmente por parte da vogal alta /i/ na variedade do interior paulista.

O fator vogal média-alta presente na sílaba seguinte à da pretônica/e/, em nomes, como em prot [e]tora, é identificado como neutro em relação ao alçamento (PR 0.514) e, em verbos, como em $p$ [e]nsei, é desfavorecedor do fenômeno (PR 0.385). Já o fator vogal média-baixa ou baixa na sílaba seguinte à da pretônica-alvo é desfavorecedor do alçamento de /e/, com PRs significativamente baixos: 0.185 e 0.072 , respectivamente para nomes, como em $v[e] l o ́ r i o$, e verbos, como em esp[e]rar.

Para as rodadas relativas à pretônica /o/, observam-se os resultados a seguir.

Tabela 3 -Alçamento de /o/ em nomes e verbos em relação à altura da vogal presente na sílaba subsequente à sílaba da pretônica-alvo

\begin{tabular}{c|c|c|c|c} 
& \multicolumn{2}{c}{ Pretônica /o/ - Nomes } & \multicolumn{2}{c}{ Pretônica /o/ - Verbos } \\
\cline { 2 - 5 } & Frequência & PR & Frequência & PR \\
\hline Alta anterior & $33,9 \%(61 / 180)$ & 0.866 & $41,6 \%(52 / 125)$ & 0.915 \\
\hline Alta posterior & $15,8 \%(6 / 38)$ & 0.666 & $54,5 \%(12 / 22)$ & 0.994 \\
\hline Média-alta & $6,2 \%(14 / 226)$ & 0.418 & $16,2 \%(103 / 634)$ & 0.649 \\
\hline Média-baixa & $44 \%(40 / 91)$ & 0.809 & $5,4 \%(2 / 37)$ & 0.327 \\
\hline Baixa & $2 \%(4 / 199)$ & 0.109 & $1 \%(4 / 400)$ & 0.127 \\
\hline Total & \multicolumn{1}{|c}{$17 \%(125 / 734)$} & 14,2\% (173/1218) \\
\hline
\end{tabular}

Para /o/, verifica-se, novamente, grande influência da vogal alta anterior na realização do alçamento em nomes (PR 0.866), como em $d[u]$ mingo, e em verbos (PR 0.915), como em c[u]zinhar. O fator vogal alta posterior na sílaba seguinte à da pretônica-alvo também é apontado como favorecedor do alçamento de /o/ em nomes (PR 0.666), como em op [u]rtunidade, e, principalmente, em verbos (PR 0.994), como em pr[u]curar. Apesar de o resultado ir ao encontro do esperado, indicando o fator vogal alta posterior como favorecedor do alçamento (por meio de harmonização vocálica) em ambas as classes gramaticais, observam-se, como feito para a vogal pretônica /e/, as ocorrências de alçamento da pretônica /o/ com vogal alta posterior na sílaba subsequente. Além da vogal alta na sílaba seguinte, todas as ocorrências podem ser explicadas pela adjacência de uma consoante dorsal, como em c[u]stureira e pr[u]curar, e/ou labial, como em op[u]rtunidade e c[u]mputação. Portanto, nesses casos, o alçamento também pode ser explicado pelo processo de redução vocálica. No entanto, não se nega a influência da 
vogal alta posterior na aplicação do alçamento de /o/, dados os PRs altos apresentados para nomes e verbos (cf. tabela 3).

De certo modo, em relação ao processo de harmonização vocálica, pode-se comparar a variedade do interior paulista com a do Estado do Rio Grande do Sul. No falar gaúcho, Bisol (1981) verificou que a vogal / $\mathrm{u} /$ favorece o alçamento de /o/, mas exerce comportamento inibidor da harmonização vocálica de /e/ (PR 0.39), como apontado pelo programa estatístico para a vogal pretônica/e/ em nomes no interior paulista (PR 0.319). A partir desse resultado, Bisol (1981, p. 61) afirma que "não se pode atribuir indiscriminadamente o papel de condicionador da regra da harmonização vocálica à vogal alta, pois tudo indica que o assimilador por excelência da regra de /e/ é a vogal/i/, enquanto na regra de /o/, ambas as vogais desempenham este papel".

No que tange à presença de vogal média-alta na sílaba subsequente à da pretônica-alvo, em nomes, como em c[o]ntrole, esse fator é desfavorecedor do alçamento (PR 0.418) e, em verbos, como em $c[u] n h e c e u$, favorece a realização do fenômeno (PR 0.649). O resultado obtido na rodada dos verbos não era esperado, pois as vogais médias-altas não funcionam como gatilho ao alçamento. Dessa forma, foram verificados os 103 casos de alçamento de vogal pretônica /o/ seguida por vogal média-alta, constatando-se que o alçamento pode ser explicado por redução vocálica, dada a existência de consoante dorsal e/ou labial em posição adjacente à pretônica-alvo. ${ }^{15}$

Portanto, os resultados que apontam as vogais médias-altas como favorecedoras do alçamento de /o/ estão enviesados pela redução vocálica decorrente da influência do(s) ponto(s) de articulação de consoante(s) adjacente(s).

Outro resultado não esperado é o favorecimento do alçamento de /o/ por parte das vogais médias-baixas em nomes, como em $c[u]$ lega (PR 0.809). Por consistirem em vogais mais baixas do que as médias-altas, esperava-se que esse contexto fosse desfavorecedor da aplicação do alçamento. Como explicação para esse resultado, verifica-se que, das 40 ocorrências de alçamento, 31 (77,5\%) dizem respeito somente a dois itens lexicais (de um mesmo paradigma): $m[u] l e q u e$ e $m[u] l e q u i n h o$. Esses itens podem ter seu alçamento explicado por redução vocálica, tendo em vista a presença da consoante precedente labial, que, como descrito mais adiante, favorece o alçamento de /o/. Dessa maneira, esses itens lexicais enviesam os resultados, que mostram as vogais médias-baixas na sílaba seguinte como favorecedoras do alçamento de /o/ em nomes.

Quanto à vogal /o/ em verbos, a presença de vogal média-baixa na sílaba subsequente, como em ac[o]ntece, desfavorece o alçamento (PR 0.327). Também desfavorece o alçamento da vogal pretônica posterior a presença de vogal baixa em nomes, como em j[o]rnal (PR 0.109), e em verbos, como em pr[o]var (PR 0.127).

\footnotetext{
${ }^{15} \mathrm{~A}$ exceção é o vocábulo ch[u]rei, cuja vogal pretônica é antecedida e seguida por consoantes coronais. Entretanto, a consoante precedente à pretônica-alvo /o/ é a fricativa alveopalatal desvozeada, que apresenta ponto de articulação alto e que, dessa forma, engatilha a redução vocálica da pretônica.
} 
Para o cruzamento das variáveis altura e tonicidade da vogal presente na sílaba subsequente à sílaba da pretônica-alvo, foram realizadas novas rodadas para as vogais médias pretônicas em nomes e em verbos, separadamente. A princípio, foram considerados todos os fatores da variável altura da vogal presente na sílaba subsequente à sílaba da pretônica-alvo. Todavia, houve nocautes em todas as rodadas. Após o amálgama a fim de serem resolvidos esses nocautes, foram observados resultados enviesados pelo maior número de ocorrências em certos fatores e, além disso, a ausência de outros dificultava a realização de uma análise comparativa dos resultados das quatro rodadas. Tendo em vista o objetivo inicial de se observar a (a)tonicidade de vogais altas, optou-se, com base nos fatos apresentados, por excluir os fatores referentes às demais alturas das vogais (médias-altas, médias-baixas e baixa), como ilustra a tabela $4 .{ }^{16}$

Tabela 4-Alçamento de /e/ em nomes e verbos em relação ao cruzamento das variáveis altura e tonicidade da vogal presente na sílaba subsequente à sílaba da pretônica-alvo ${ }^{17}$

\begin{tabular}{|c|c|c|c|c|}
\hline & \multicolumn{2}{|c|}{ Pretônica /e/ - Nomes } & \multicolumn{2}{|c|}{ Pretônica /e/ - Verbos } \\
\hline & Frequência & PR & Frequência & PR \\
\hline Alta anterior tônica & $49,5 \%(91 / 184)$ & 0.736 & $62,8 \%(184 / 293)$ & 0.609 \\
\hline Alta anterior átona & $16,5 \%(26 / 158)$ & 0.330 & $55,2 \%(48 / 87)$ & 0.283 \\
\hline Alta posterior tônica & $11,9 \%(5 / 42)$ & 0.184 & 1 & I \\
\hline Alta posterior átona & $12,5 \%(1 / 8)$ & 0.140 & $34,2 \%(13 / 38)$ & 0.214 \\
\hline Total & \multicolumn{2}{|c|}{$31,4 \%(123 / 392)$} & \multicolumn{2}{|c|}{$58,6 \%(245 / 418)$} \\
\hline & $\begin{array}{l}\text { Input: } 0.264 \\
\text { ignif.: } 0.006\end{array}$ & & $\begin{array}{l}\text { put: } 0.505 \\
\text { nif.: } 0.008\end{array}$ & \\
\hline
\end{tabular}

Para a vogal pretônica /e/, o fato de ser tônica a vogal /i/ que engatilha o alçamento é bastante relevante, pois foram encontrados PRs altos para a alta anterior tônica em nomes, como em fli]rida (PR 0.736), e em verbos, como em s[i]guía (PR 0.609), ao passo que foram obtidos PRs baixos para o fator alta anterior átona também em nomes, como em int [e]ligente (PR 0.330), e em verbos, como em r[e]gistrou (PR 0.283).

No que diz respeito à vogal-gatilho /u/, sua tonicidade não se mostra relevante para o alçamento de /e/ em nomes, já que tanto o fator alta posterior tônica, como em p[e]rgunta, quanto o fator alta posterior átona, como em r[e]cuperação, obtiveram PRs baixos (0.184 e 0.140, respectivamente). Para verbos, essa informação não pode ser avaliada com exatidão, devido à escassez de dados para o fator vogal alta posterior tônica. Para esse fator, houve apenas duas ocorrências (formas verbais p[e]rgunta e p[e]rguntam), sendo que nenhuma apresentou alçamento, resultando em nocaute. Por esse motivo, essas ocorrências foram descartadas. De

\footnotetext{
${ }^{16} \mathrm{~A}$ variável resultante do cruzamento altura e tonicidade foi selecionada nas quatro novas rodadas.

${ }^{17} \mathrm{Nas}$ tabelas 4 e 5, o símbolo "/" indica que as ocorrências prévias foram descartadas devido a nocaute.
} 
qualquer maneira, observa-se que a vogal alta posterior átona, como em $p[e] r g u n t o u$, mostra-se desfavorecedora do alçamento de /e/ em verbos (PR 0.214).

Em relação à vogal pretônica /o/, os resultados constam na tabela a seguir:

Tabela 5 - Alçamento de /o/ em nomes e verbos em relação ao cruzamento das variáveis altura e tonicidade da vogal presente na sílaba subsequente à sílaba da pretônica-alvo

\begin{tabular}{|c|c|c|c|c|}
\hline & \multicolumn{2}{|c|}{ Pretônica /o/ - Nomes } & \multicolumn{2}{|c|}{ Pretônica /o/ - Verbos } \\
\hline & Frequência & PR & Frequência & PR \\
\hline Alta anterior tônica & $48,1 \%(52 / 108)$ & 0.751 & $59,3 \%(48 / 81)$ & 0.717 \\
\hline Alta anterior átona & $12,5 \%(9 / 72)$ & 0.226 & $9,1 \%(4 / 44)$ & 0.075 \\
\hline Alta posterior tônica & $11,8 \%(2 / 17)$ & 0.310 & 1 & 1 \\
\hline Alta posterior átona & $19 \%(4 / 21)$ & 0.310 & $52,4 \%(11 / 21)$ & 0.843 \\
\hline Total & \multicolumn{2}{|c|}{$30,7 \%(67 / 218)$} & \multicolumn{2}{|c|}{$43,2 \%(63 / 146)$} \\
\hline & \multicolumn{2}{|l|}{$\begin{array}{l}\text { Input: } 0.120 \\
\text { Signif.: } 0.047\end{array}$} & $\begin{array}{l}\text { at: } 0.280 \\
\text { if.: } 0.003\end{array}$ & \\
\hline
\end{tabular}

Para a vogal pretônica /o/, foi encontrado resultado semelhante ao apresentado para a pretônica /e/ no que tange à influência da vogal-gatilho /i/: quando tônica, esta vogal favorece o alçamento em nomes, como em c[u]mpridas (PR 0.751), e em verbos, como em desc[u]bri (PR 0.717). Quando átona, desfavorece o alçamento também em nomes, como em $m$ [o]vimento (PR 0.226), e em verbos, como em c[0]nsiderava (PR 0.075).

No que diz respeito à vogal / $\mathrm{u} /$ como gatilho do alçamento de /o/, para os nomes, a tonicidade dessa vogal não consiste em uma informação relevante, pois o PR do fator alta posterior tônica, como em $v[0]$ lüme, é exatamente o mesmo do fator alta posterior átona, como em c[o]mputador (PR 0.310). Para os verbos, um resultado que não se esperava encontrar é o grande favorecimento (PR 0.843) da vogal alta posterior átona para o alçamento de /o/. No entanto, quando observadas as 11 ocorrências, uma corresponde ao vocábulo ac[u]stumẹi, cinco a verbos do paradigma de $c[u]$ sturar e cinco a formas verbais do paradigma de $p r[u] c u r a r$. Todas as ocorrências podem ser explicadas pela influência de consoante adjacente dorsal / $\mathrm{k} /$, ou seja, pelo processo de redução vocálica. Além disso, os dez últimos dados parecem corroborar a proposta da difusão lexical, pelo fato de o alçamento ocorrer, sobretudo, em vocábulos que apresentam paradigmas em comum. De qualquer forma, o descarte do fator alta posterior tônica - pelo nocaute decorrente da existência de uma única ocorrência (alçada): c[u]stümo - impossibilita a análise sistemática da tonicidade da vogal / u/ como relevante para a harmonização vocálica da pretônica /o/ em verbos.

Em suma, constatam-se resultados muito similares para as pretônicas /e/e /o/, atestando que a tonicidade da vogal-gatilho /i/ é relevante para a harmonização vocálica, ao contrário do que diz respeito à vogal-gatilho/u/. Para ambas as vogais médias pretônicas, no entanto, a 
tonicidade da vogal alta não é determinante para a realização do processo no interior paulista, visto que há ocorrências de alçamento engatilhado por vogal alta átona, o que vai ao encontro das constatações de Bisol (1981) para a variedade gaúcha.

Outra afirmação de Bisol (1981) é a de que a contiguidade da sílaba da vogal alta em relação à da pretônica-alvo é um fator obrigatório para a aplicação da harmonização vocálica. Desse modo, investigou-se, neste trabalho, a variável distância entre a sílaba da vogal alta em relação à sílaba da pretônica-alvo. Para essa variável, a princípio, foram considerados três fatores, sendo eles: (i) vogal alta presente na sílaba seguinte à da pretônica-alvo; (ii) uma sílaba entre as sílabas da vogal pretônica-alvo e a da vogal alta; e (iii) duas sílabas entre as sílabas da vogal pretônica e a da vogal alta. Contudo, não houve ocorrências de /e/ e de /o/ em verbos com distância de duas sílabas entre a pretônica-alvo e a vogal alta. Quanto aos nomes, nas rodadas de /e/ e /o/, foi necessário o amálgama de fatores, por ter sido apontado nocaute no fator duas sílabas entre a vogal pretônica-alvo e a alta. Para /e/, houve cinco casos que distavam duas sílabas, a saber: $d[e]$ legacia, irr[e]sponsabilidade, pr[e]ferencial, $r[e]$ sponsabilidade e $v[e] g e t a t i v o$. Para /o/, houve apenas uma ocorrência ( $c[0]$ leçãozinh $a)$. Nenhuma dessas seis ocorrências apresentou alçamento, resultando, portanto, em nocaute. Por conseguinte, nas rodadas dos nomes, esse fator foi amalgamado com o fator uma sílaba entre as sílabas da vogal pretônica-alvo e a da vogal alta. Os resultados dessa variável são apresentados a seguir.

Tabela 6 - Alçamento de /e/ em nomes e verbos em relação à distância entre a sílaba da vogal alta em relação à sílaba da pretônica-alvo

\begin{tabular}{|c|c|c|c|c|}
\hline & \multirow{2}{*}{\multicolumn{2}{|c|}{ Pretônica /e/ - Nomes }} & & \\
\hline & & & \multicolumn{2}{|c|}{ Pretônica /e/ - Verbos } \\
\hline & Frequência & \multirow{2}{*}{$\begin{array}{c}\text { PR } \\
0.440\end{array}$} & \multirow{2}{*}{\begin{tabular}{|c|} 
Frequência \\
$58,6 \%(245 / 418)$
\end{tabular}} & \multirow{2}{*}{$\begin{array}{c}\text { PR } \\
0.420\end{array}$} \\
\hline $\begin{array}{l}\text { Vogal alta presente na sílaba } \\
\text { seguinte à da pretônica-alvo }\end{array}$ & $31,4 \%(123 / 392)$ & & & \\
\hline $\begin{array}{l}\text { Uma ou duas sílabas entre a vogal } \\
\text { pretônica-alvo e a vogal alta }\end{array}$ & $11,1 \%(10 / 90)$ & 0.742 & $39,5 \%(17 / 43)$ & 0.958 \\
\hline Total & \multicolumn{2}{|c|}{$27,6 \%(133 / 482)$} & \multicolumn{2}{|c|}{$56,8 \%(262 / 461)$} \\
\hline \multicolumn{2}{|c|}{ Input: 0.104} & & \multicolumn{2}{|l|}{ nput: 0.052} \\
\hline
\end{tabular}

Em relação à distância, pode-se verificar que o fator uma ou duas sílabas entre a sílaba da vogal alta em relação à da pretônica-alvo, como em esp[e]táculo e d[e]veria, é o favorecedor do alçamento da pretônica /e/ em nomes (PR 0.742) e, principalmente, em verbos (PR 0.958). Esses resultados são diferentes do esperado e estão enviesados pela pouca quantidade de dados nesse contexto ( 90 nomes e 43 verbos) em comparação com o maior número de ocorrências de vogal pretônica que apresenta vogal alta na sílaba imediatamente seguinte (392 nomes e 418 verbos), como em j[e]jum e acr[e]dito. 
De qualquer forma, observa-se que as porcentagens de alçamento não apresentam tendência semelhante à das probabilidades. No fator que considera a contiguidade da vogal alta, as porcentagens (31,4\% para nomes e 58,6\% para verbos) são maiores do que as encontradas para a vogal pretônica que dista uma ou duas sílabas em relação à sílaba da vogal alta (11,1\% para nomes e $39,5 \%$ para verbos).

Quanto à pretônica /o/, essa variável foi selecionada apenas para os verbos. No que diz respeito a essa classe gramatical, foram obtidos resultados similares aos de /e/, como pode ser verificado por meio da tabela seguinte:

Tabela 7 - Alçamento de /o/ em verbos em relação à distância entre a sílaba da vogal alta em relação à sílaba da pretônica-alvo

\begin{tabular}{c|c|c}
\cline { 2 - 3 } & \multicolumn{2}{c}{ Pretônica /o/ - Verbos } \\
\cline { 2 - 3 } & Frequência & PR \\
\hline Vogal alta presente na sílaba seguinte à da pretônica-alvo & $43,5 \%(64 / 147)$ & 0.450 \\
\hline Uma ou duas sílabas entre a vogal pretônica-alvo e a vogal alta & $17,1 \%(12 / 70)$ & 0.604 \\
\hline Total & \multicolumn{2}{c}{$35 \%(76 / 217)$} \\
\hline
\end{tabular}

Input: 0.050

Signif.: 0.048

Assim como nas rodadas da pretônica /e/ em nomes e em verbos, na rodada de /o/ em verbos, o fator uma ou duas sílabas entre a sílaba da vogal pretônica-alvo e a da vogal alta, como em

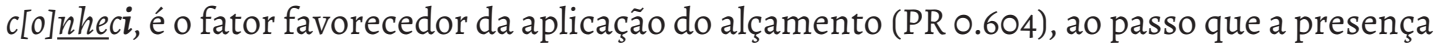
de vogal alta na sílaba seguinte, como em $m[0] r r i$, é levemente desfavorecedora do fenômeno (PR 0.450). No entanto, a porcentagem maior corresponde ao fator que considera a vogal alta na sílaba seguinte à da pretônica-alvo (43,5\%), ao passo que o índice percentual menor corresponde à distância maior entre essas vogais (17,1\%).

Bisol (1981) aponta a obrigatoriedade da contiguidade da vogal alta em relação à pretônica-alvo para a aplicação da harmonização vocálica, o que os resultados parecem, a princípio, refutar. Entretanto, considerando-se as ocorrências de alçamento em vocábulos que apresentam uma sílaba de distância entre a sílaba da pretônica-alvo e a da vogal alta, pode-se notar que, no caso da vogal pretônica /o/ em verbos, todas as ocorrências podem ser explicadas por redução vocálica, por meio da influência de consoante(s) adjacente(s). Em c[u]nheci e c[u]nhecia, por exemplo, a consoante dorsal [k] ocupa posição precedente à pretônica-alvo, assim como a consoante labial [p] em $p[u] d e r i a$. As consoantes dorsais e labiais, em contexto precedente à pretônica /o/ em verbos, favorecem o alçamento dessa vogal (cf. CARMO, 2013). Em pr[u]metia, a consoante labial [m] ocupa a posição imediatamente seguinte à pretônica-alvo, contexto que também é favorecedor da aplicação do fenômeno. Ainda em contexto seguinte, deve-se destacar a palatal em $c[u] n h e c i$ e $c[u]$ nhecia, que, por seu ponto de articulação alto, também pode influenciar o alçamento. 
Quanto à vogal pretônica/e/, das 27 ocorrências totais (10 nomes e 17 verbos), 25 apresentam vogais alçadas - ou seja, pronunciadas como alta - na sílaba imediatamente seguinte, como em pr[i]f[i]rível e p[i]qu[i]nininha. Essas vogais alçadas passam a servir de gatilho à aplicação do alçamento da vogal pretônica. As únicas exceções são trav[i]sseirinho e d[i]sconfiar.

Quanto ao substantivo trav[i]sseirinho, Bisol (1981) aponta que, para o falar gaúcho, o sufixo -inho(a) tende a inibir a realização da harmonização vocálica, por atuar no âmbito da fronteira do vocábulo. Segundo a autora, "não se tratando de mera adjunção de um sufixo, a harmonização vocálica que só atua no nível da palavra, fica bloqueada pela juntura de limite de vocábulo que esses sufixos levam à esquerda” (BISOL, 1981, p. 104-105). Além disso, apesar de não estar presente nos dados levantados por esta pesquisa, a forma trav[i]sseiro é encontrada na variedade do interior paulista. Quanto ao verbo d[i]sconfiar, o alçamento da pretônica /e/ ocorre recorrentemente, mesmo quando não há vogal alta na sílaba seguinte (ou sequer no vocábulo), como em d[i]spesa, $d[i]$ screver e $d[i]$ spertou. Esses fatos mostram que o alçamento em trav[i]sseirinho e d [i]sconfiar não ocorre por influência da vogal alta e, portanto, não se trata de harmonização vocálica, mas de redução vocálica.

Desse modo, verifica-se que as 39 ocorrências (10 de /e/ em nomes, $17 \mathrm{de} / \mathrm{e} / \mathrm{em}$ verbos e 12 de /o/ em verbos) apresentam alçamento por outros motivos que não a influência direta da altura da vogal presente com uma sílaba de distância, o que corrobora a afirmação de Bisol (1981) de ser essencial, para a aplicação da harmonização vocálica, a contiguidade da sílaba da vogal alta em relação à da pretônica-alvo.

Analisadas as vogais médias pretônicas na variedade investigada, são apresentadas, a seguir, as considerações finais desta pesquisa.

\section{CONSIDERAÇÕES FINAIS}

O presente artigo sumariza os principais resultados da tese de Doutorado de Carmo (2013) sobre o comportamento variável das vogais médias pretônicas em contexto medial na variedade do noroeste paulista.

Constata-se que o alçamento dessas vogais é resultado, sobretudo, de informações de natureza linguística, com destaque à atuação do processo de harmonização vocálica, visto que a altura da vogal presente na sílaba subsequente à sílaba da pretônica-alvo foi apontada como a variável mais relevante para a aplicação do alçamento, independentemente da classe gramatical (nomes ou verbos).

Sobre esse processo, observa-se que age da seguinte forma: a vogal alta, especialmente a anterior /i/ - dada a posição mais alta da língua no momento de sua emissão (BISOL, 1981) -, engatilha o alçamento quando presente na sílaba imediatamente seguinte à da pretônica-alvo. Além disso, esse processo é favorecido quando a vogal gatilho é, também, a tônica do vocábulo. 
Consequentemente, atesta-se um comportamento relativamente similar das vogais médias pretônicas mediais na variedade do noroeste paulista em relação às vogais presentes no mesmo contexto linguístico no falar gaúcho (BISOL, 1981).

Por fim, destacam-se os resultados apresentados no presente trabalho, por contribuírem para o mapeamento das vogais médias pretônicas no interior paulista e, de maneira mais abrangente, no PB, dado o vínculo desta investigação ao Projeto Nacional PROBRAVO.

\section{REFERÊNCIAS}

ABAURRE-GNERRE, M. B. M. Processos fonológicos segmentais como índices de padrões prosódicos diversos nos estilos formal e casual do português do Brasil. Caderno de Estudos Lingüísticos, Campinas, v. 2, p. 23-44, 1981.

BISOL, L. Harmonia vocálica: uma regra variável. 1981. 280 f. Tese (Doutorado em Linguística) - Faculdade de Letras, Universidade Federal do Rio de Janeiro, Rio de Janeiro, 1981.

BISOL, L. O alçamento da pretônica sem motivação aparente. In: BISOL, L; COLLISCHONN, G. (Org.) Português do Sul do Brasil - variação fonológica. Porto Alegre: EDIPUCRS, 2009, p. 73-92.

CALVET, L. J. Sociolinguística: uma introdução crítica. Tradução de Marcos Marcionilo. São Paulo: Parábola, 2002. (Primeira edição em 1993).

CÂMARA JR., J. M. Estrutura da língua portuguesa. 40. ed. Petrópolis: Vozes, 2007. (Primeira edição em 1970).

CARMO, M. C. As vogais médias pretônicas dos verbos na fala culta do interior paulista. 2009. 119 f. Dissertação (Mestrado em Estudos Linguísticos) - Instituto de Biociências, Letras e Ciências Exatas, Universidade Estadual Paulista, São José do Rio Preto, 2009.

CARMO, M. C. As vogais médias pretônicas na variedade do interior paulista. 2013. 249 f. Tese (Doutorado em Estudos Linguísticos) - Instituto de Biociências, Letras e Ciências Exatas, Universidade Estadual Paulista, São José do Rio Preto, 2013.

CARMO, M. C. Alçamento vocálico das vogais médias pretônicas iniciais na variedade do noroeste paulista. Revista Estudos Linguísticos. v. 48, n. 2, p. 800-821, jul. 2019.

CARMO, M. C.; TENANI, L. E. As vogais médias pretônicas na variedade do noroeste paulista. Alfa: Revista de Linguística. v. 57, n. 2, p. 607-637, 2013.

CHAMBERS, J. K. Sociolinguistic Theory. (Rev. Ed.). Singapore: Wiley-Blackwell, 2009. (Primeira edição em 1995).

COLLISCHONN, G. A sílaba em português. In: BISOL, L. (Org.) Introdução a estudos de fonologia do Português Brasileiro. 2. ed. Porto Alegre: EDIPUCRS, 1999, p. 91-119.

GONÇALVES, S. C. L. O português falado na região de São José do Rio Preto: constituição de um banco de dados anotado para o seu estudo. Relatório científico final apresentado à 
FAPESP. 2007. Disponível em:<http://www.iboruna.ibilce.unesp.br/histórico/relatoriofinal>. Acesso em: 13 ago. 2008.

GONÇALVES, S. C. L. Banco de dados Iboruna: amostras eletrônicas do português falado no interior paulista. Disponível em: <iboruna.ibilce.unesp.br>. Acesso em: 14 jul. 2018.

LABOV, W. Some Sociolinguistic Principles. In: PAULSTON, C. B.; TUCKER, G. R. (Ed.) Sociolinguistics: the Essential Readings. Oxford: Blackwell, 2003, p. 234-250.

LABOV, W. Padrões sociolinguísticos. Tradução de Marcos Bagno, Maria Marta Pereira Scherre e Caroline Rodrigues Cardoso. São Paulo: Parábola, 2008. (Primeira edição em 1972).

SELKIRK, E. The Syllable. In: HULST, H.; SMITH, N. (Ed.). The Structure of Phonological Representations (Part II). Dordrecht: Foris, 1982, p. 337-383.

SILVEIRA, A. A. M. As vogais pretônicas na fala culta do noroeste paulista. 2008. $143 \mathrm{f}$. Dissertação (Mestrado em Estudos Linguísticos) - Instituto de Biociências, Letras e Ciências Exatas, Universidade Estadual Paulista, São José do Rio Preto, 2008.

WEINREICH, U.; LABOV, W.; HERZOG, M. I. Fundamentos empíricos para uma teoria da mudança lingüística. Tradução de Marcos Bagno. São Paulo: Parábola, 2006. (Primeira edição em 1968).

Recebido para publicação em 12 out. 2018. Aceito para publicação em 30 abr. 2019. 